may take large amounts of laxatives for postoperative constipation, leading to the "cathartic colon." If this had been so in our study we would have expected more use of laxatives by the women who had had hysterectomy than we found, although such use might have been underreported deliberately. Another possible mechanism is pelvic autonomic denervation due to an intraoperative manoeuvre, traction during the operation, or realignment of the pelvic organs after removal of the uterus.

Urinary dysfunction is a well recognised complication of hysterectomy and is thought to be due to disruption of the nerve supply to the bladder. We found a highly significant association between persistently reduced bowel frequency and persistently increased urinary frequency after hysterectomy. This supports the hypothesis that they may have a common aetiology-namely, autonomic denervation of both

viscera, which have a closely related nerve supply in the pelvis.

We thank Dr A A Robertson, Dr A Donald and partners, Dr M A Eastwood, and Mr J Knowles (medical records officer) for their help with this study. We also thank Dr J W Yarnell for giving us a copy of his questionnaire.

1 Connell AM, Hilton C, Irvine G, Lennard-Jones JE, Misiewic $\angle \mathrm{JJ}$., Variation of bowel habit in two population samples. Br.Med $\mathcal{F}$ 1969;ii:1095-9.

2 Yarnell JW, Voyle GJ, Richards CJ, Stephenson TP. The prevalence and severity of urinary incontinence of women. 7 Epidemiol Community Health 1981;35:71-4.

3 Coppen A, Bishop M, Beard RJ, Barnard GJR, Collins WP. Hysterectomy, hormones and behaviour: a prospective study. Lancet 1981;i:126-8.

Preston DM, Rees L.H, Lennard-Jones JE. Gynaecological disorders and hyperprolactinaemia in chronic constipation. Gut 1983;24:A480.

5 Catchpole BN. Motor pattern of left colon before and after surgery for rectal cancer: possible implications in other disorders. Gut 1988;29:624-30.

(Accepted 29 April 1989)

\title{
Radioiodine in human thyroid glands and incidence of thyroid cancer in Cumbria
}

Colin Bowlt, Peter Tiplady

Department of Radiation Biology, St Bartholomew's Hospital Medical College, London EC1M 6BQ Colin Bowlt, PHD, senior lecturer

Department of Community Medicine, East Cumbria

Health Authority, Cumberland Infirmary, Carlisle CA2 7HY

Peter Tiplady, FFCM, district medical officer

Correspondence to: $\mathrm{Dr}$ Bowlt.

Br.Med F 1989:299:301-2
Concern is increasing over the association between ionising radiation and cancers in populations living close to nuclear installations such as Sellafield in Cumbria. Because the external radiation in Cumbria is only marginally above the national average ${ }^{1}$ any appreciable additional dose would have to come from manmade sources of radioactivity.

Both iodine-129 and iodine-131 are discharged from Sellafield into the sea and the atmosphere and since the early 1960s have probably contributed equally to the small additional dose ${ }^{23}$ to the thyroid above that of natural background radiation. We measured ${ }^{129} I$ activity in thyroid glands in the population of Cumbria and related them to the incidence of thyroid cancer in the area. Inevitable delays in carrying out these measurements excluded an assessment of ${ }^{131} \mathrm{I}$, which has a half life of eight days (that of ${ }^{129} \mathrm{I}$ is 15 million years).

\section{Methods and results}

Measurements were made on 130 thyroid glands taken opportunistically at necropsy from adults (mean age 67) dying from various causes in Cumbria between

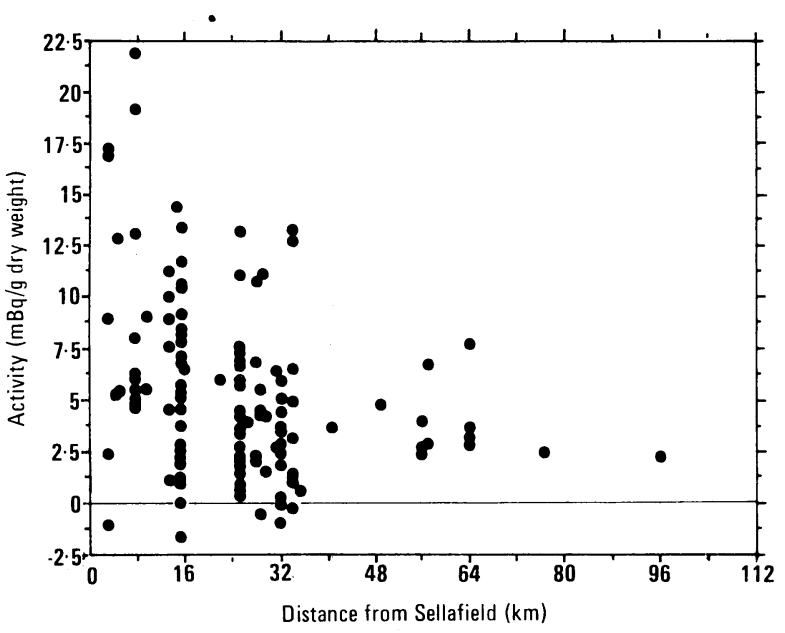

Left: ${ }^{120}$ I activity in thyroid tissue taken at necropsy related to distance of patients' homes from Sellafield. Right: registrations of thyroid cancer in Cumbria, 1969-86

$S R R=$ Standardised registration ratio
November 1984 and September 1987. The thyroid samples were homogenised and dried, and ${ }^{124}$ I activity was measured in a thin walled scintillation detector over 100 minutes. Background levels (which varied during the examination) were subtracted from the count rate for the sample, and occasional negative values resulted. The figure (left) shows ${ }^{129} \mathrm{I}$ activity in individual thyroid glands plotted against the distance of the patients' homes from Sellafield. Levels of radioactivity decreased with distance (Spearman's rho $=-0 \cdot 392, \mathrm{p}<0 \cdot 001$ )

We also examined the incidence of thyroid cancer, using data from the Northern regional cancer registry for 1969-86. Age standardised registration rates and ratios were calculated by applying the national values for the midpoint of the period. Surprisingly, there was a positive correlation between the distance from Sellafield and the incidence of cancer, with higher incidences being found with greater distance (Spearman's rho= $0.541, p=0.0007$ ) (figure (right)). In the 40 (out of 288) parishes where thyroid cancers occurred the incidence varied from $0 \cdot 39$ to $40 \cdot 46 / 100000$. Calculations using the Poisson distribution, ${ }^{4}$ however, showed only two parishes with significant increases in thyroid cancer: one was $16 \mathrm{~km}$ from Sellafield (two cases registered $v$ 0.1 expected, $\mathrm{p}<0.01$ ) and the other $24 \mathrm{~km}$ away (four cases registered $v 0.5$ expected, $\mathrm{p}<0.01$ ). In Cumbria

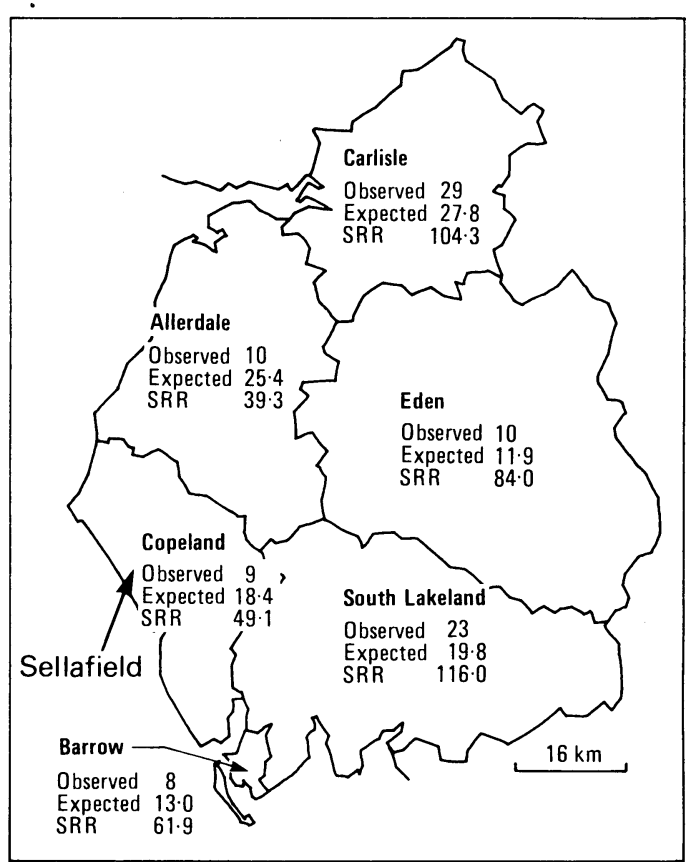


overall there were fewer cases than expected (male, 19 cases $v 31 \cdot 2$ expected; female, 71 cases $v 85 \cdot 0$ expected). Within the parishes that formed the Copeland area around Sellafield nine cases were registered compared with $18 \cdot 4$ expected.

\section{Comment}

The decrease in radioactivity with distance from Sellafield is probably due to several factors, including the pattern of distribution of milk, which is generally assumed to be the principal source of ${ }^{129}$ I. Several points emerged from the study. Firstly, the specific activities varied widely even within the same residential area. This could be due to natural variation and differing diet as well as to the varying amounts of time people spend away from their homes. Secondly, the activities were low, most being under $10 \mathrm{mBq} / \mathrm{g}$ dry weight and none above $22 \mathrm{mBq} / \mathrm{g}$. This indicates that most of the sample population received less than an additional $0.67 \mu \mathrm{Sv} /$ year from this source, ${ }^{5}$ and none are likely to have received more than an additional 1.5 $\mu \mathrm{Sv} / \mathrm{year}$. This is small compared with the dose to the thyroid from normal background radiation, which in the Sellafield area is about $1000 \mu \mathrm{Sv} /$ year. Any cancers induced by this additional dose of ${ }^{129} \mathrm{I}$ are therefore unlikely to be detected above the natural incidence of the disease.

Even if higher levels of radioactivity occurred in the past these have not produced any detectable increase in the incidence of thyroid cancer. Two parishes with a significantly increased incidence were some distance from Sellafield; the increased incidence would therefore seem to be unrelated to any radioactive discharge from the nuclear fuel reprocessing works.

1 Stather JW' Wrixon AD, Simmonds JR. The risk of leukaemia and other cancers in Seascale from radiation exposure. London: HMSO, 1984. (National Radiological Protection Board report R171

2 Stather JW, Dionian J, Fell TP, Muirhead CR. The risks of leukaemia and other cancers in Seascale from radiation exposure. London: HMSO, 1986. (National Radiological Protection Board report R171 addendum.)

3 Greenhalgh JR, Fell TP, Adams N. Dose from intakes of radionuclides by adults and young people. London: HMSO, 1985. (National Radiological Protection Board report R162.

4 Baillar JC, Ederer F. Significance factors for the ratio of a Poisson variable to its expectation. Biometrics 1964; 20:639-43.

5 Snyder WS, Ford MR, Warner GC, Watson SB. Absorbed dose per unit cumulated activity for selected radionuclides and organs. $7 \mathrm{Nucl} \mathrm{Med}$ 1975; Medical Internal Radiation Dose Committee pamphlet 11.

(Accepted 24 April 1989)

\title{
Extension of selection criteria for extracorporeal shock wave lithotripsy for gall stones
}

\author{
A Darzi, J R T Monson, C O'Morain, \\ W A Tanner, F B V Keane
}

Departments of Clinical Surgery and Gastroenterology, Meath Hospital, Dublin 8

A Darzi, $\mathrm{MB}$, registrar in general surgery

J R T Monson, FRCS, registrar in general surgery

CO'Morain, FRCP, consultan physician

W A Tanner, FRCSI, consultant surgeon

F B V Keane, FRSC, consultant surgeon

Correspondence to: Mr Keane.

BrMed f 1989;299:302-3
Extracorporeal shock wave lithotripsy and dissolution treatment for gall stones have yielded encouraging results. ${ }^{12}$ Selection criteria, however, seem arbitrary and based on those already established for treatment with bile salts. ${ }^{3}$ As such criteria may restrict the number of patients treated we therefore extended the criteria and report our experience.

\section{Patients, methods, and results}

We treated 62 patients as outpatients between August 1987 and June 1988 (12 male, 50 female; mean age 46 (range 11-81)). Patients were selected if they had (a) symptomatic gall stone disease; $(b)$ radiolucent stones of any size or number or radio-opaque stones $\leqslant 3 \mathrm{~cm}$; and $(c)$ a functioning gall bladder on oral

Clearance of gall stones with shock wave lithotripsy in 49 patients based on stone profile

\begin{tabular}{|c|c|c|c|c|c|}
\hline \multirow[b]{2}{*}{ No of stones } & \multirow[b]{2}{*}{ Size of stones $(\mathrm{cm})$} & \multicolumn{4}{|c|}{ Clearance of stones } \\
\hline & & $100 \%$ & $\geqslant 50 \%$ & $<50 \%$ & 0 \\
\hline \multicolumn{6}{|c|}{ Radiolucent stones } \\
\hline 1 & $\left\{\begin{array}{l}<1 \\
2-3 \\
3-5\end{array}\right.$ & $\begin{array}{l}1 \\
6\end{array}$ & 1 & $1^{\star}$ & $\begin{array}{l}2 \\
1^{\star}\end{array}$ \\
\hline 2,3 & $\left\{\begin{array}{l}<1 \\
2-3\end{array}\right.$ & $\begin{array}{l}3 \\
1\end{array}$ & $\begin{array}{l}2 \\
2\end{array}$ & & \\
\hline$\geqslant 4$ & $\left\{\begin{array}{l}<1 \\
2-3\end{array}\right.$ & $\begin{array}{c}12^{\star} \\
1^{\star}\end{array}$ & $\begin{array}{l}4^{\star} \\
1^{\star}\end{array}$ & $1^{\star}$ & $\begin{array}{l}2^{\star} \\
1^{\star}\end{array}$ \\
\hline \multicolumn{6}{|c|}{ Radio-opaque stones } \\
\hline $\begin{array}{l}1 \\
2,3\end{array}$ & $\begin{array}{l}2-3 \\
2-3\end{array}$ & $1^{\star}$ & & & $2^{\star}$ \\
\hline$\geqslant 4$ & $\left\{\begin{array}{l}<1 \\
2-3\end{array}\right.$ & $\begin{array}{l}1^{\star} \\
1^{\star}\end{array}$ & & & $\begin{array}{l}1^{\star} \\
1^{\star}\end{array}$ \\
\hline Total & & 27 & 10 & 2 & 10 \\
\hline
\end{tabular}

$\star$ Patients who would not have been eligible for treatment with established selection criteria. cholecystography. Thirteen patients were excluded: four failed to return after the first treatment, two emigrated, one became pregnant, and two could not tolerate bile salt treatment; lithotripsy was abandoned in four because of difficulty in visualising the gall bladder.

All patients received combination dissolution treatment comprising chenodeoxycholic and ursodeoxycholic acid $7 \mathrm{mg} / \mathrm{kg} /$ day each, administered as one tablet (Lithofalk), and one capsule of a terpene mixture (Rowachol) three times daily. Ultrasonography was used to focus the shock waves from a piezoelectric lithotripter on the stones within the gall bladder. Each patient received 6000 shock waves in each treatment session (frequency 2.5 shock waves/s, $100 \%$ power) up to a maximum of six treatments at intervals of two to three weeks. All patients were followed up every month clinically and by ultrasonography. Two consecutive ultrasound scans and an oral cholecystogram were required to establish that the stones had been cleared.

The 49 patients received 175 sessions of shock wave treatment, each patient requiring an average of three treatments (range one to six). The table shows the outcome related to number, size, and type of stones. We classified patients into four groups. One group comprised those in whom all stones were cleared $(n=27$; median follow up six months $(95 \%$ confidence interval 4.8 to $7 \cdot 5$ ) to time of clearance). The second group comprised those with $\geqslant 50 \%$ clearance - that is, fragmentation with appreciable clearance of stones ( $\mathrm{n}=10$; median follow up nine months). The third group comprised those with $<50 \%$ clearance - that is, fragmentation with little clearance of stones $(\mathrm{n}=2$; median follow up seven months). The fourth group comprised patients who had insignificant fragmentation or clearance of fragments after six treatment sessions and follow up of six months $(n=10)$.

Thirty one patients, including 16 of the 27 in whom all stones were cleared, would not have been deemed suitable for lithotripsy by previous criteria. ${ }^{12}$ Lithotripsy was generally well tolerated. Eight patients suffered biliary colic during follow up, which usually occurred within 48 hours after lithotripsy. One patient in whom treatment failed had transient jaundice four days after treatment, which resolved spontaneously. None had skin ecchymosis or haematuria or any clinical or biochemical evidence of acute pancreatitis. 